\title{
Effects of Sintering Temperature on Densification, Microstructure and Mechanical Properties of Al-Based Alloy by High-Velocity Compaction
}

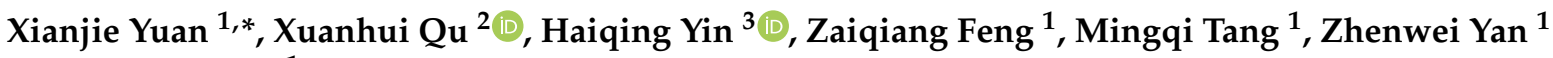 \\ and Zhaojun Tan ${ }^{1}$ \\ 1 School of Mechanical Engineering, North China University of Water Resources and Electric Power, \\ Zhengzhou 450045, China; fengzaiqiang@ncwu.edu.cn (Z.F.); tangmingqi@ncwu.edu.cn (M.T.); \\ yanzhenwei@ncwu.edu.cn (Z.Y.); 13603990078@163.com (Z.T.) \\ 2 Institute for Advanced Materials and Technology, University of Science and Technology Beijing, \\ Beijing 100083, China; quxh@ustb.edu.cn \\ 3 Collaborative Innovation Center of Steel Technology, University of Science and Technology Beijing, \\ Beijing 100083, China; hqyin@ustb.edu.cn \\ * Correspondence: xjyuan@ncwu.edu.cn; Tel.: +86-0371-6912-7259
}

check for updates

Citation: Yuan, X.; Qu, X.; Yin, H.; Feng, Z.; Tang, M.; Yan, Z.; Tan, Z. Effects of Sintering Temperature on Densification, Microstructure and Mechanical Properties of Al-Based Alloy by High-Velocity Compaction. Metals 2021, 11, 218.

https://doi.org/10.3390/ met11020218

Received: 30 December 2020

Accepted: 20 January 2021

Published: 26 January 2021

Publisher's Note: MDPI stays neutra with regard to jurisdictional claims in published maps and institutional affiliations.

Copyright: (c) 2021 by the authors. Licensee MDPI, Basel, Switzerland. This article is an open access article distributed under the terms and conditions of the Creative Commons Attribution (CC BY) license (https:// creativecommons.org/licenses/by/ $4.0 /)$.

\begin{abstract}
This present work investigates the effects of sintering temperature on densification, mechanical properties and microstructure of Al-based alloy pressed by high-velocity compaction. The green samples were heated under the flow of high pure (99.99 $\mathrm{wt} \%) \mathrm{N}_{2}$. The heating rate was $4{ }^{\circ} \mathrm{C} / \mathrm{min}$ before $315^{\circ} \mathrm{C}$. For reducing the residual stress, the samples were isothermally held for one $\mathrm{h}$. Then, the specimens were respectively heated at the rate of $10^{\circ} \mathrm{C} / \mathrm{min}$ to the temperature between $540{ }^{\circ} \mathrm{C}$ and $700{ }^{\circ} \mathrm{C}$, held for one $\mathrm{h}$, and then furnace-cooled to the room temperature. Results indicate that when the sintered temperature was $640{ }^{\circ} \mathrm{C}$, both the sintered density and mechanical properties was optimum. Differential Scanning Calorimetry, X-ray diffraction of sintered samples, Scanning Electron Microscopy, Energy Dispersive Spectroscopy, and Transmission Electron Microscope were used to analyse the microstructure and phases.
\end{abstract}

Keywords: high-velocity compaction; Al-based alloy; sintering process

\section{Introduction}

The powder metallurgy (PM) route provides lower energy consumption, higher material utilisation and excellent machinability in aluminium [1]. PM technology can present a homogeneous microstructure with little segregation compared with the casting method [2]. Therefore, Al-based PM alloy is currently an area of rapid development. The automotive industry is the main consumer of Al-based PM parts because of the lightweight and cost-effective nature of this process [3]. Al-based PM camshaft bearing caps were firstly introduced with the commercial inception of this technology in the mid-1990s. In recent decades, Al-based PM materials have been developed to expand the application of the automobile field [4-6]. Efforts have largely addressed the development of PM counterparts to wrought or cast alloys that span a broad range of properties [7-9].

There are two main problems in the current research: 1) the effect of porosity of existing green on sintering performance. The existence of a few residual porosities in the sintered parts remains the hurdle to get over for many applications, although the newer Al-based alloys offer main strength improvements [10]. High-velocity compaction (HVC) has greatly enhanced the density of the green body [11,12]. Z. H. Zhang et al. [13] reported that the iron-base PM alloy parts with high performance and high density were obtained by the combination of HVC and powder annealing. K. Q. Zhang et al. [14] explored a data-driven model for green density prediction by the multilayer perceptron algorithm and optimised the processing parameters of HVC-based metallic powders. D. D. You et al. [15] 
reported that a green compact with a $98 \%$ relative density is produced using pure iron powders with HVC. 2) It is difficult to sinter Al alloy, because there is a stable alumina film which coats the powder particles and hinders the material transfer between particles during sintering. A lot of mechanisms for alumina film reaction or disruption have been offered. Z. Wang et al. [16] reported that the surface oxide layer of the Al alloy powders was broken during hot pressing by a processing route imposing local deformation between the nanoscale phases rather than between consolidated powders, and the mechanical properties were improved. A. Ibrahim et al. [17] studied sintering temperature, pressing pressure, and the effect of heat treatment to Alumix 321 and the theoretical density of $98 \%$ was achieved. Sintering in PM is generally defined as a process or phenomenon occurring with heating green powder compact under appropriate temperature and atmosphere. The sintering plays a decisive role in the performance of the final products [18]. The sintering temperature has great effects on the microstructures and the properties of the material. Moreover, an appropriate sintering temperature can contribute to the attainment of the economic sintering process since they can help to reduce the energy consumption of the sintering process [19]. The authors studied the effects of compaction velocity on sintered density and mechanical properties of Al-based alloy, and the results were published [20]. The previous study showed that the higher velocity of HVC contributed to the increasing of sintered density and mechanical properties of Al-based alloy.

The aim of this work was to study the best-sintered temperature for the Al-based alloy during the powder metallurgy process. The research was therefore performed to find the highest tensile strength of the sample while, at the same time, density remains in an acceptable range. Al-based alloy powder was high velocity compacted and sintered with different temperatures $\left(540{ }^{\circ} \mathrm{C}-700{ }^{\circ} \mathrm{C}\right)$ for one $\mathrm{h}$. The effect of sintering temperature on densification, mechanical properties and microstructure of Al-based alloy were studied.

\section{Experimental Details}

In this research, the compaction methods and raw materials of green were the same as the previous study. The main chemical compositions of the Al-based alloy powder were $\mathrm{Al}, \mathrm{Fe}, \mathrm{Cr}$, Ti and chemical compositions (in wt\%) were shown in [20].

Al-based alloy powder was pressed by the HYP 35-2 HVC machine (Hydropulsor Company, Karlskoga, Sweden). The flowchart of this process is illustrated in our previous research [11]. The green with compaction energy $1325 \mathrm{~J}$ was sintered in a tube furnace with flowing high purity nitrogen $(99.99 \mathrm{wt} \%)$. The heating rate was $4{ }^{\circ} \mathrm{C} / \mathrm{min}$ before $315^{\circ} \mathrm{C}$. For reducing the residual stress, the samples were isothermally holding for one $\mathrm{h}$ at $315^{\circ} \mathrm{C}$. Then, it was respectively heated at the rate of $10^{\circ} \mathrm{C} / \mathrm{min}$ to the temperature between $540{ }^{\circ} \mathrm{C}$ and $700{ }^{\circ} \mathrm{C}$, held for one $\mathrm{h}$, and then furnace-cooled to room temperature. The low-temperature heating rate, high-temperature heating rate, low-temperature holding temperature and other parameters used in this experiment are the best parameters optimised by previous experiments. The optimal sintering process is the one after the best sintering temperature is determined. As a comparison, the green with compaction energy of $1885 \mathrm{~J}$ was sintered under the optimal sintering process $7 \%$ of the ethylenediamine solution, powder particles, and $93 \%$ of the epoxy resin were mixed and then the mixture carefully into the mould of the round pipe. After leaving it for $24 \mathrm{~h}$, the sample can be ground. The upper surface of this powder sample, green and sintered samples were ground smooth to observe the microstructure. The scanning electron microscope (SEM) of samples were observed by JSM-6510 (JEOL, Tokyo, Japan). The elemental distributions were analysed by energy dispersive spectroscopy (EDS) with the SEM. The evolution of phases was performed by field emission scan electron microscope (FE-SEM, ZEISS ULTRA55, ZEISS, Oberkochen, Germany). The phase analysis was performed by a transmission electron microscope (TEM, FEI Tecnai G2 F20 S-Twin, FEI, Hillsborough, OR, USA). The temperature range of melting point of the alloy was measured by a differential scanning calorimetry (DSC) method (Netzsch STA 449C, Selb, Germany) performed in the range of $40-900{ }^{\circ} \mathrm{C}$ at a constant heating rate of $10^{\circ} \mathrm{C} / \mathrm{min}$. The Archimedean method, according to the ASTM 
B962-08, was applied to obtain the sintered density. Phase identifications of samples were examined on an X-ray diffractometer (XRD, Siemens D5000, Munich, Germany) with a Cu Ka radiation source operated at a continuous scanning rate of $5{ }^{\circ} \mathrm{C} / \mathrm{min}$, current of $40 \mathrm{~mA}$ and a voltage of $40 \mathrm{kV}$.

The tensile tests were performed at room temperature. An Instron universal testing machine was used to stretch the samples until failure at a constant cross-head speed of $0.5 \mathrm{~mm} / \mathrm{min}$. All of the samples were cut with the GB/T 228.1-2010. The ultimate tensile strength (UTS), $0.2 \%$ yield strength (YS) and elongation $(\delta)$ of each temperature or compaction velocity were obtained as the average of their test results.

\section{Results and Discussion}

\subsection{Effect of Sintering Temperature on Densification}

Sintering is a heating process that causes particles to bond together, resulting in significant strengthening and improved properties [21]. The sintering temperature is the most important factor affecting alloying due to the thermal activation of diffusion [18].

In this experiment, the theoretical density of Al-based alloy was $2.92 \mathrm{gcm}^{-3}$ [20], and, with the increasing of sintering temperature, the sintered density gradually increased. The experimental results are consistent with the Arrhenius diffusion coefficient equation. Figure 1a reveals the effect of sintering temperature on sintered density. The plots show that the sintered density of the samples increases with an increase in sintering temperature, with obvious densification occurring when the temperature increases from $620^{\circ} \mathrm{C}$ to $640^{\circ} \mathrm{C}$. As shown in Figure 1a, the sintered density rapidly increases from $2.73 \mathrm{gcm}^{-3}$ (relative density is $93.49 \%$ ) to $2.8 \mathrm{gcm}^{-3}$ (relative density is $95.89 \%$ ) when the sintering temperature increases from $560{ }^{\circ} \mathrm{C}$ to $640{ }^{\circ} \mathrm{C}$. The sintered density increases slowly from $2.8 \mathrm{gcm}^{-3}$ (relative density is $95.89 \%$ ) to 2.81 (relative density is $96.23 \%$ ) $\mathrm{gcm}^{-3}$ when the sintering temperature increases from $640{ }^{\circ} \mathrm{C}$ to $700^{\circ} \mathrm{C}$. During the sintering process of the green, with the increasing of sintering temperature, the powder particles boundary developed from poor mechanical bonding to strong metallurgical bonding, and internal pores of the green become smaller or disappear. The driving force is generally considered as the reduction of free energy at the expense of minimising the internal and external surfaces [22]. While density increases significantly when the sintering temperature increase from 650 to $700{ }^{\circ} \mathrm{C}$, serious deformation of the sample is also observed as shown in Figure 1a. In fact, the higher sintering temperature does not appear to be the best. Figure 2 is the DSC of Al-based alloy powder. Figure 2 reveals that the Al-based alloy begins to melt at $658{ }^{\circ} \mathrm{C}$ and the melting point is $658^{\circ} \mathrm{C}$. The samples began to deform at $650{ }^{\circ} \mathrm{C}$ due to the partial melting, which may hurt the mechanical properties of the compact, which occurred when the specimen was sintered at $650{ }^{\circ} \mathrm{C}$. These were considered to be unsuitable for an industrial production environment because they negated the near net shape property for which PM manufacturing relies on [23]. Therefore, considering the influence of sintering temperature on sintered density and near net shape, $640^{\circ} \mathrm{C}$ is the optimum sintering temperature. The effect of sintering temperature on the properties of the alloy will be further verified, and then the sintering temperature will be finally determined.

Nevertheless, the samples sintered at $640{ }^{\circ} \mathrm{C}$ had a lower sintered density $2.8 \mathrm{gcm}^{-3}$ (relative density is $95.89 \%$ ), because the green density was lower when the compaction energy is $1325 \mathrm{~J}$ as shown in Figure $1 \mathrm{~b}$. Figure $1 \mathrm{~b}$ indicates that sintered density and green density increase as the compaction energy increase. When the compaction energy increased from $1325 \mathrm{~J}$ to $1885 \mathrm{~J}$, sintered density increased by $0.05 \mathrm{gcm}^{-3}$ (relative density is $2.11 \%$ ). During the HVC, the compaction energy was transferred to the powder particles in a short time to make them densification. The higher the compaction energy contributed to enhancing the green density, which increased the contact area between adjacent powder particles and facilitated sintering densification. Therefore, HVC was beneficial to sintering. 

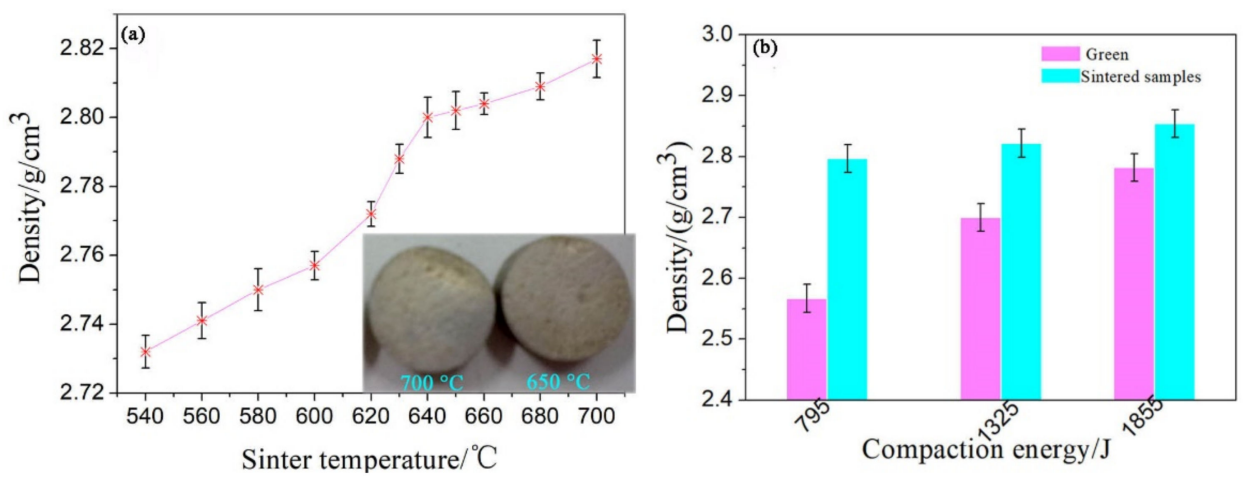

Figure 1. (a) Sintered density versus sintering temperature: all specimens were compacted with compaction energy of $1325 \mathrm{~J}$ and sintered for $60 \mathrm{~min}$ at temperature; (b) Sintered density versus compaction energy.

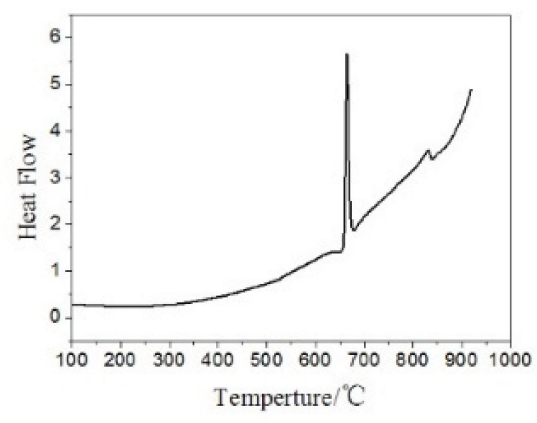

Figure 2. The differential scanning calorimetry (DSC) of Al-based alloy powder.

\subsection{Microstructure and Phases Constitution}

Figure 3 shows the SEM microstructure of the atomised Al-based alloy powder with different magnification and the green sample with the compaction energy of $1325 \mathrm{~J}$. From Figure $3 a$, it is clear that the large particle mainly contains a white phase and the little particle contains a grey phase with the dispersive distribution. Figure $3 \mathrm{~b}$ shows the white phase in the large particles distributes as snowflakes. Figure $3 c$ exhibits a large number of small pores which are irregular and uneven distribution and obvious particle boundaries. This is because the compaction energy $1325 \mathrm{~J}$ is not high enough. Figure 4 shows the XRD patterns of Al-based alloy powder and green. It mainly consists of the $\mathrm{Al}, \mathrm{Al}_{3} \mathrm{Ti}$, and quasicrystalline phase (Q-phase). This assumption is in agreement with data reported by M. Galano [24], describing that the Q-phase is an icosahedral quasicrystalline phase. On the other hand, the peak width of each phase of the green is significantly wider than that of the powder, as shown in Figure 4. This confirms that the plastic deformation of the powder particles during the HVC. Under the action of external force, plastic deformation in different regions of the green is different, which leads to the inconsistency of microstrain, so that, for the same crystal surface index, the crystal surface spacing in different regions is different. 


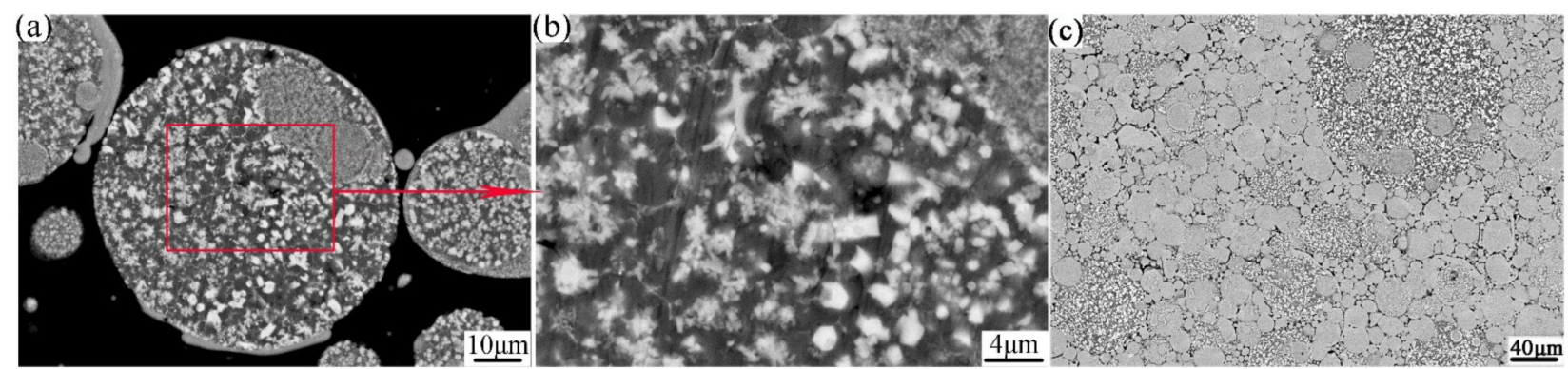

Figure 3. (a) lower amplification (b) higher amplification SEM/BSE of the atomised powder particles; (c) SEM/BSE of the green sample with the compaction energy of $1325 \mathrm{~J}$.

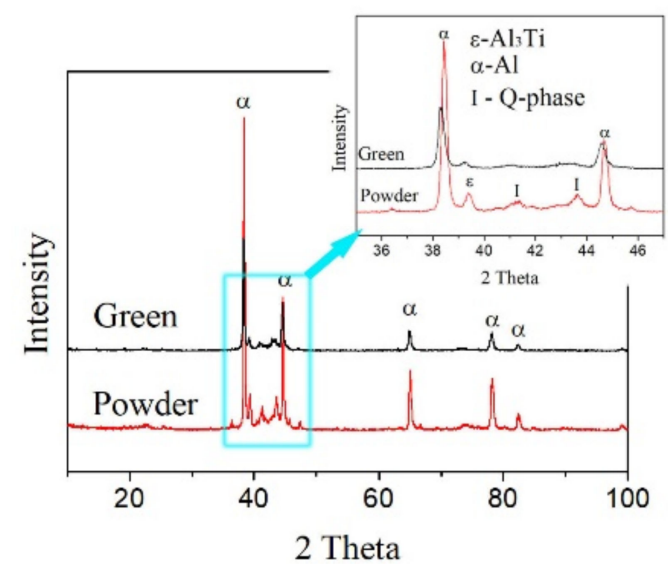

Figure 4. X-ray diffraction (XRD) pattern of Al-based alloy powder and green.

Microstructure analysis of the sintered specimens was carried out to research the development of the evolution of the porosity and the microstructure. The microstructure of sintered samples with different sintering temperatures, as shown in Figure 5. The evolution of pores can be comparatively seen in Figure 5 with the sintering temperature increasing. Figure 5a exhibits the samples sintered at $560{ }^{\circ} \mathrm{C}$ have many pores and distinct original particle boundaries. This shows that the number of atoms participating in diffusion is small due to the low diffusion coefficient at $560{ }^{\circ} \mathrm{C}$ and the particles are still in contact which demonstrates a lack of metallurgical bonding. Clear original particle boundaries and many pores can be observed in Figure $5 \mathrm{~b}$ when the sintering temperature is $580^{\circ} \mathrm{C}$, but the contact area between particles increases. This phenomenon indicates that the sintered neck began to form at $580{ }^{\circ} \mathrm{C}$ and the contact between particles began to change from mechanical meshing to metallurgical bonding with the sintered temperature and according to increase in the diffusion coefficient. Figure $5 \mathrm{c}$ shows that the samples have fewer pores and original particle boundaries, and the adjacent particles gain the contact area when the sintering temperature is $620^{\circ} \mathrm{C}$. This result exhibited that the sintered neck began to grow at $620{ }^{\circ} \mathrm{C}$ and the metallurgical bonding between particles gained. Figure $5 \mathrm{~d}$ presents the sample has less porosity and original particle boundaries, and the contact area between the adjacent particles continue to gain when the sintering temperature is $640{ }^{\circ} \mathrm{C}$. This result exhibited that the sintered neck continued to grow up at $640{ }^{\circ} \mathrm{C}$ and the metallurgical bonding between particles enhanced. On the other hand, gas atomised Al powder-coated amorphous $\mathrm{Al}_{2} \mathrm{O}_{3}$ (a-Al2O3) film [25], and L. Cao et al. [26] found that the a- $\mathrm{Al}_{2} \mathrm{O}_{3}$ turn into $\gamma-\mathrm{Al}_{2} \mathrm{O}_{3}$ nanoparticles during SPS (Spark plasma sintering) causing a dramatic increase in the elongation to fracture. For HVC, the high impact force of the HVC offered a mechanical means to disrupt the $\mathrm{Al}_{2} \mathrm{O}_{3}$ film due to the larger amount of deformation of the ductile Al-based powder [27]. The powder particles in this experiment were spherical, as shown in Figure 6a. The surface of small particles is smooth, and the surface of large particles is uneven, as shown in Figure 6b. When the spherical particles 
were impacted by high energy, the impact force on the particles was greater due to the smaller contact area between the spheres, and it was easier to break the oxide film locally. When the compaction energy is $1885 \mathrm{~J}$, as shown in Figure 5e the elimination of porosity and the dissolution of the particles for the sintered sample at $640{ }^{\circ} \mathrm{C}$ can be observed.
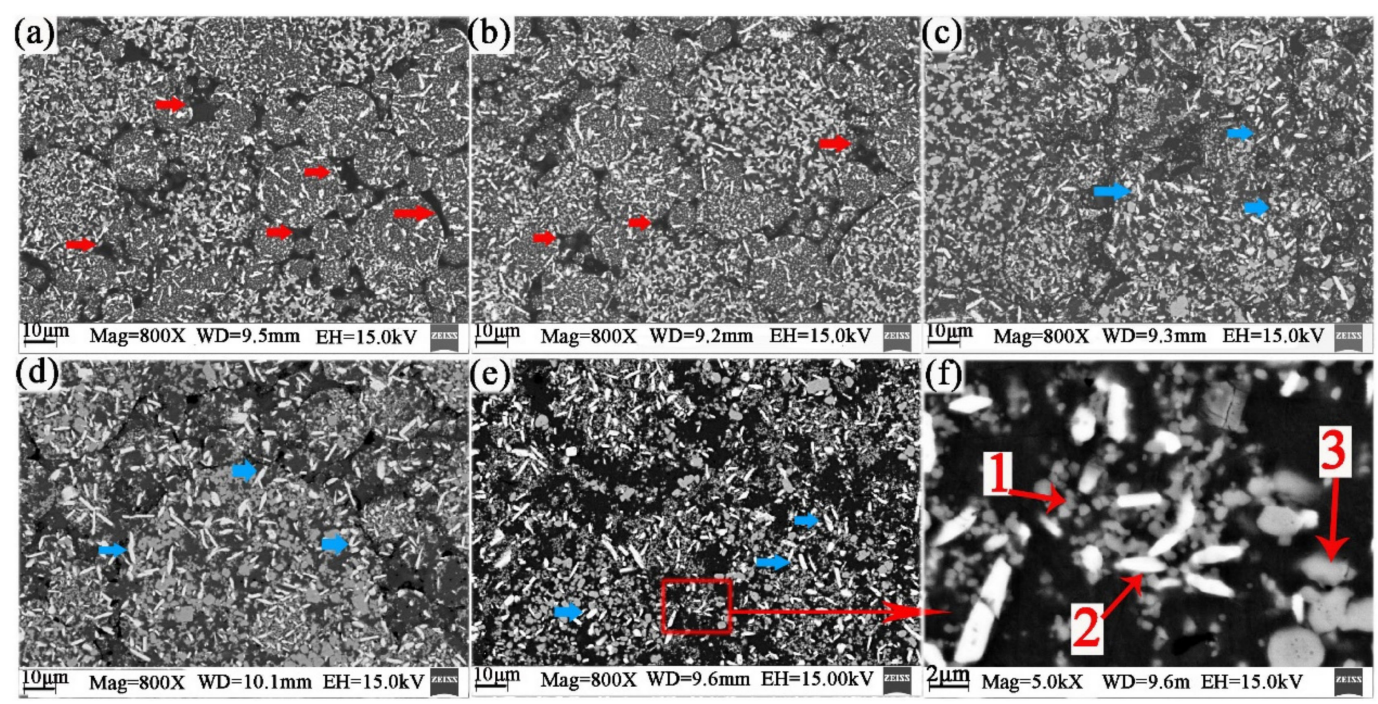

Figure 5. FESEM/BSE micrograph of the green and sintered samples with different sintering temperature: specimens were compacted with compaction energy of $1325 \mathrm{~J}$ and sintered at temperature, (a) $560{ }^{\circ} \mathrm{C}$ (b) $580{ }^{\circ} \mathrm{C}$ (c) $620^{\circ} \mathrm{C}$ (d) $640{ }^{\circ} \mathrm{C}$; and specimens were compacted with compaction energy of $1885 \mathrm{~J}$ and sintered at $640{ }^{\circ} \mathrm{C}(\mathbf{e}, \mathbf{f})$.

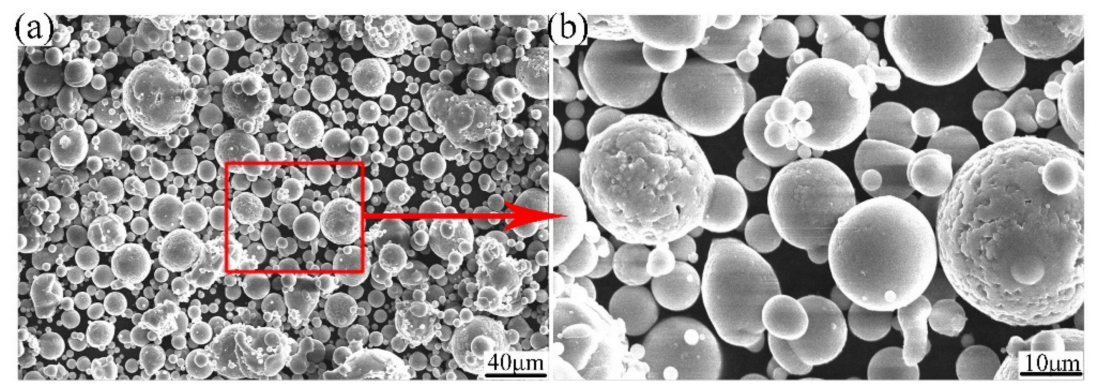

Figure 6. SEM image (a) and particle size distribution (b) of atomised Al-based alloy powders.

After sintering, the phase transition is very obvious with the increase in sintering temperature we can see the formation of white acicular phase and flaky grey phase, as shown in Figure 5a,b. As shown in Figure 5c-e, the white phase and grey phase evident grow up and the white phase moves to the particle boundary or across particle boundaries. From Figure 5f, it is clearly shown that the phases of the sample are composed of white phase 2, grey phase 3 and dispersed nano phase 1. Further analysis of the EDS presents the composition of phases, as shown in Table 1. XRD patterns of the sintered Al-based alloy samples, fabricated at $560^{\circ} \mathrm{C}, 600^{\circ} \mathrm{C}, 640^{\circ} \mathrm{C}$, and $660^{\circ} \mathrm{C}$, are shown in Figure 7. As it can be seen in Figure 7, the spectrums of all the samples have characteristic peaks of $\mathrm{Al}$ and a small amount of $\mathrm{Al}_{3} \mathrm{Ti}, \mathrm{Al}_{13} \mathrm{Fe}_{4}, \mathrm{Al}_{13} \mathrm{Cr}_{2}, \mathrm{AlN}$ and $\mathrm{AlCr}_{2}$. The absence of quasicrystalline phase after sintering is due to the decomposition of the quasicrystalline phase at the high temperature [24]. The exothermic peaks of these phases decomposition are not observed on the DSC (Figure 2), because these phases only exist when the particle size is less than $25 \mu \mathrm{m}$ [20]. The average particle size of the experimental powder is $25 \mu \mathrm{m}$, and the content of these phases is very small, which is almost invisible in the DSC experiment. There is no obvious new phase formation with the sintering temperature increasing, as shown in Figure 7. However, as the sintering temperature increasing, the angle of the peak becomes larger. For example, when the sintering temperature is $660^{\circ} \mathrm{C}$, peaks become wider 
and move to the right. This is because diffusion enhanced as the sintering temperature increasing. In Figure 8, SEM images together with detailed element distribution maps of $\mathrm{Al}, \mathrm{Fe}, \mathrm{Cr}$, and Ti elements are shown. The EDS maps confirm that the main component of the white acicular phase is $\mathrm{Fe}$, flake phase is $\mathrm{Ti}$, and the finely dispersed nano phase is $\mathrm{Cr}$. The combination of XRD and EDS results revealed the formation of the higher $\mathrm{Cr}$ content of phase $\mathrm{Al}_{13} \mathrm{Cr}_{2}$, the higher Fe content of phase $\mathrm{Al}_{13} \mathrm{Fe}_{4}$, and the higher Ti content of phase $\mathrm{A}_{13}$ Ti. As shown in Figure 9, it can be seen that there are granular intermetallic compounds less than $0.5 \mu \mathrm{m}$ and columnar intermetallic compounds. The constituent of 1 , 2, 3 phases in TEM, as shown in Figure 9. TEM further verified the existence of intermetallic compounds. Phase 1 is $\mathrm{Al}_{13} \mathrm{Cr}_{2}$, phase 2 is $\mathrm{Al}_{3} \mathrm{Ti}$, and phase 3 is $\mathrm{Al}_{13} \mathrm{Fe}_{4}$. The results are consistent with the previous analysis [18]. There is a small amount of $\mathrm{AlN}$ and $\mathrm{AlCr}_{2}$, and they are not verified because of the small quantity. Because the protective atmosphere of sintering is $\mathrm{N}_{2}$, AlN was formed by the reaction of $\mathrm{N}_{2}$ and $\mathrm{Al}$, such as the reaction equation $2 \mathrm{Al}+\mathrm{N}_{2} \rightarrow 2 \mathrm{AlN}$. This is a strongly exothermic reaction. The heat released may cause local melting, which will be conducive to sintering [28].

Table 1. The energy dispersive spectroscopy (EDS) of the three phases of the arrow in the microstructures of the sample.

\begin{tabular}{cccccc}
\hline Element & Phase & Al & Ti & Cr & Fe \\
\hline Atomic\% & 1 & 87.94 & 2.08 & 6.88 & 3.10 \\
Atomic\% & 2 & 77.52 & 0.37 & 0.75 & 21.36 \\
Atomic\% & 3 & 77.64 & 21.41 & 0.74 & 0.21 \\
\hline
\end{tabular}
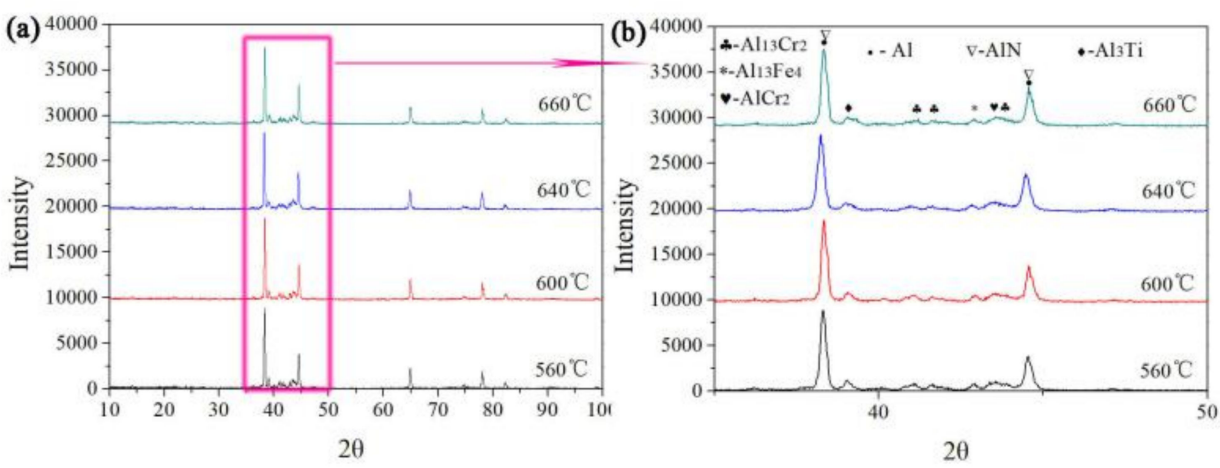

Figure 7. XRD of the sintered samples with different sintering temperature: (a) full scan from 10 to $100^{\circ}$ (b) enlargement of the 30 to $50^{\circ}$ section.

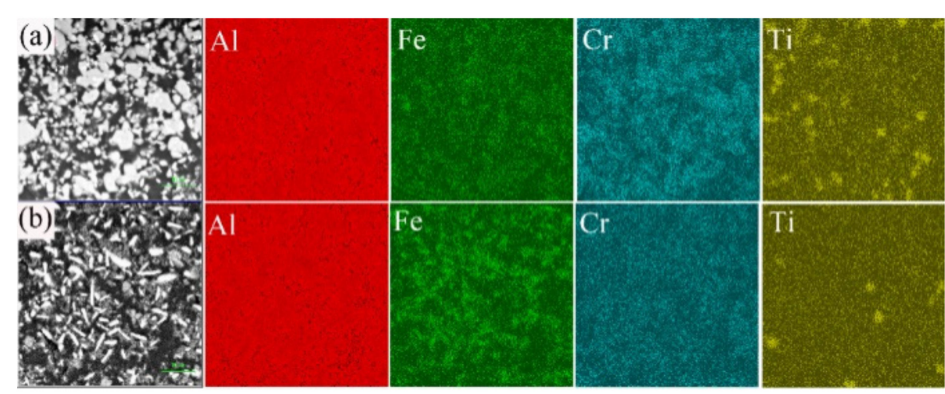

Figure 8. $\mathrm{Al}, \mathrm{Fe}, \mathrm{Cr}$, Ti element EDS mapping of (a) flake phase and (b) acicular phase of samples with sintering temperature of $640{ }^{\circ} \mathrm{C}$. 

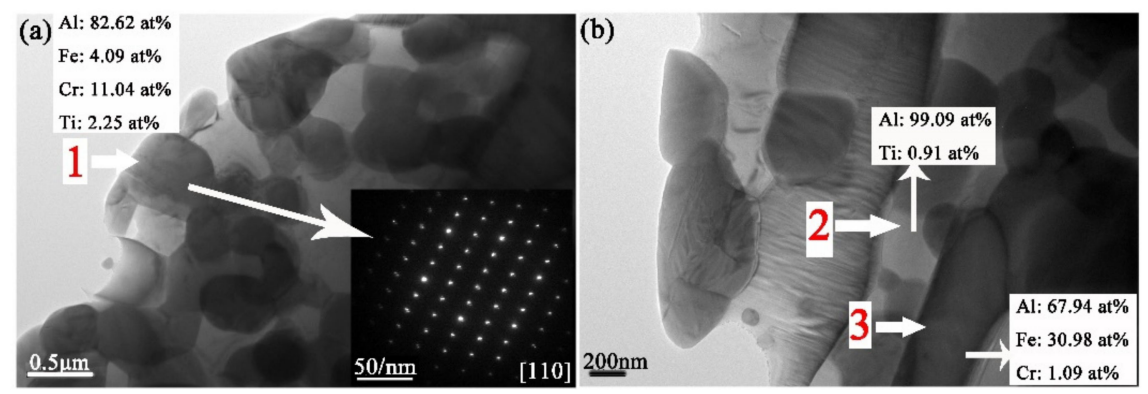

Figure 9. TEM of the sintered samples with sintering temperature $640{ }^{\circ} \mathrm{C}$ : (a) lower amplification; (b) higher amplification.

\subsection{Mechanical Property}

Tensile properties of the sintered samples with different sintered temperature are presented in Figure 10a. It can be seen from Figure 10a that the UTS, YS and $\delta$ all increase at first and then decrease with increasing the sintered temperature. Figure 10 displays UTS and YS reach the maximum (UTS $179 \mathrm{MPa}$ and YS $148 \mathrm{MPa}$ ), and the maximum $\delta$ is $1 \%$ at the sintered temperature of $640^{\circ} \mathrm{C}$. Over $640^{\circ} \mathrm{C}$, UTS, YS, and $\delta$ tend to drop. The worst UTS, YS, and $\delta$ belong to the sample fabrication at the lowest sintering temperature of $560{ }^{\circ} \mathrm{C}$. The tensile strength is $16 \mathrm{MPa}$ which is consistent with the previously measured value [29] for the bending strength of the green is $14 \mathrm{MPa}$ when the compaction energy is $1325 \mathrm{~J}$. It seems that the mass transport phenomenon has slightly transpired at $560^{\circ} \mathrm{C}$. The $\mathrm{YS}$ of the sintered sample is zero before $600^{\circ} \mathrm{C}$, and it was sharply increased to $143 \mathrm{MPa}$ at $620^{\circ} \mathrm{C}$. The $\delta$ is very low before $620^{\circ} \mathrm{C}$ is zero. Over $640^{\circ} \mathrm{C} \delta$ is also zero. The samples sintered at $640{ }^{\circ} \mathrm{C}$ still had a lower UTS, YS and $\delta$ when the compaction energy was $1325 \mathrm{~J}$ which is related to the lower compaction energy of green, as shown in Figure 10b. We can see from Figure 10b, as the compaction energy increased from $1325 \mathrm{~J}$ to $1885 \mathrm{~J}$, UTS increased by 44 , YS increased by $12 \mathrm{MPa}$, and the maximum $\delta$ increased by $1.6 \%$ respectively. Hence, it seems that the tensile properties strongly depend on the compaction energy, similar to the trend was observed for sintered density. With compaction energy increasing, the porosity of the green decreased, and the contact area between particles increased, which was helpful to the mass diffusion between the particle boundaries during sintering. Although the quasicrystal phase decomposed, the tensile properties of samples still increased with the increase in temperature. Therefore, it seems that the decomposition of the Q-phase during the sintering did not have an important detrimental effect on the improvement in the strength of the Al-based alloy [30]. Intermetallic compounds got from the decomposition of the Q-phase are the one reason for increasing the tensile strength of the alloy. Tensile properties can be related to the porosity content, phase growth, and the particle boundary, respectively.
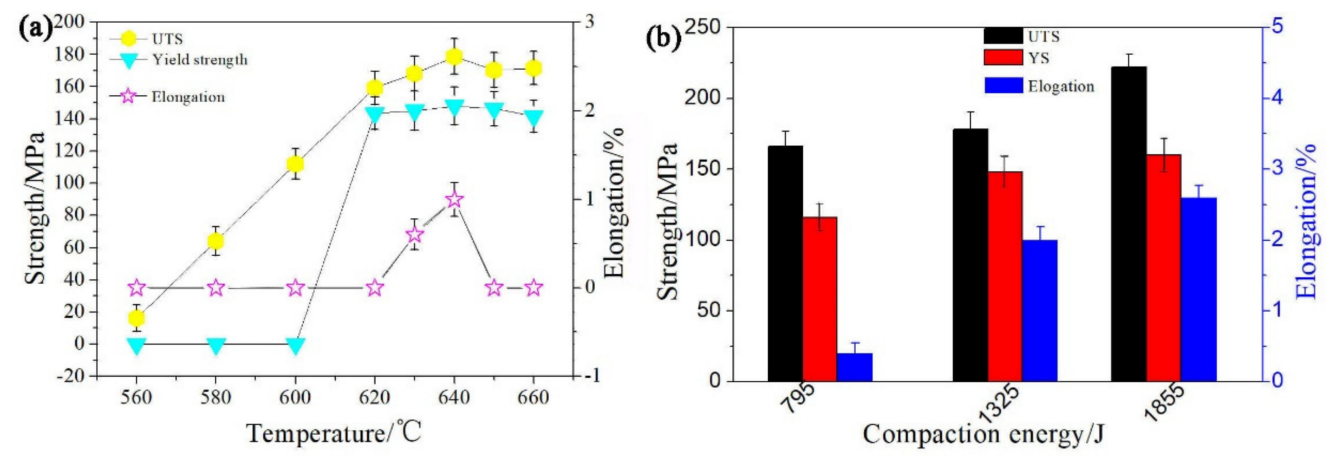

Figure 10. Ultimate tensile strength (UTS), yield strength (YS) and elongation versus sintering temperature (a); UTS, YS and elongation versus compaction energy (b). 


\subsection{Fractography}

There is a noticeable evolution on a microscopic level, which can be appreciated by comparing the fracture surface morphology with the increase in temperature, as shown in Figure 11. The original particle boundary is evident before $620^{\circ} \mathrm{C}$, which is shown in Figure 11a,b. The existence of the original particle boundary was due to the inadequate sintering, and the diffusion between particles was prevented. At $620^{\circ} \mathrm{C}$ (Figure 11c), the bond of particles began to appear, but the boundary of the original particle can still be seen, because the sintering temperature is not high, and the sintering is not sufficient. The fracture morphology of $650{ }^{\circ} \mathrm{C}$ (Figure 11e) and $660^{\circ} \mathrm{C}$ (Figure 11f) is seen as clear gullies, which is due to excessively high sintering temperature promoting the formation of the local liquid phase. This is consistent with the results of the DSC of Al-based alloy powder (Figure 2). Therefore, over $640^{\circ} \mathrm{C}$, there was evidence of excessive melting phenomenon, which shows groove structure in the fracture morphology (Figure 11e,f). At $640{ }^{\circ} \mathrm{C}$ (Figure 11d), there is a good bond between the particles, and the original particle boundary cannot be seen, but a small number of pores can still be seen. We attribute the phenomenon to the reason for the lower compaction energy (1325 J) of green. With increasing compaction energy, the bond of the original particle boundary increased obviously for the sintered sample. Figure 12a is the fracture surface morphology of the sample with compaction energy $1885 \mathrm{~J}$ and sintered at $640{ }^{\circ} \mathrm{C}$, there is a good bond between the particles, and basically cannot be seen the original particle boundary and pores. Higher magnification of the fracture surface morphology is shown in Figure 12b,c. From Figure 12b,c, fine and deep dimples are observed, indicating that the fracture mechanism is ductility fracture when the sample sintered at $640{ }^{\circ} \mathrm{C}$ with compaction energy $1885 \mathrm{~J}$. This is consistent with the analysis of tensile properties. Combined with the sintered density, the microstructure and phase analysis, the particle boundary strengthening is helpful in developing tensile properties. Hence, $640{ }^{\circ} \mathrm{C}$ was selected as the optimum sintering temperature.

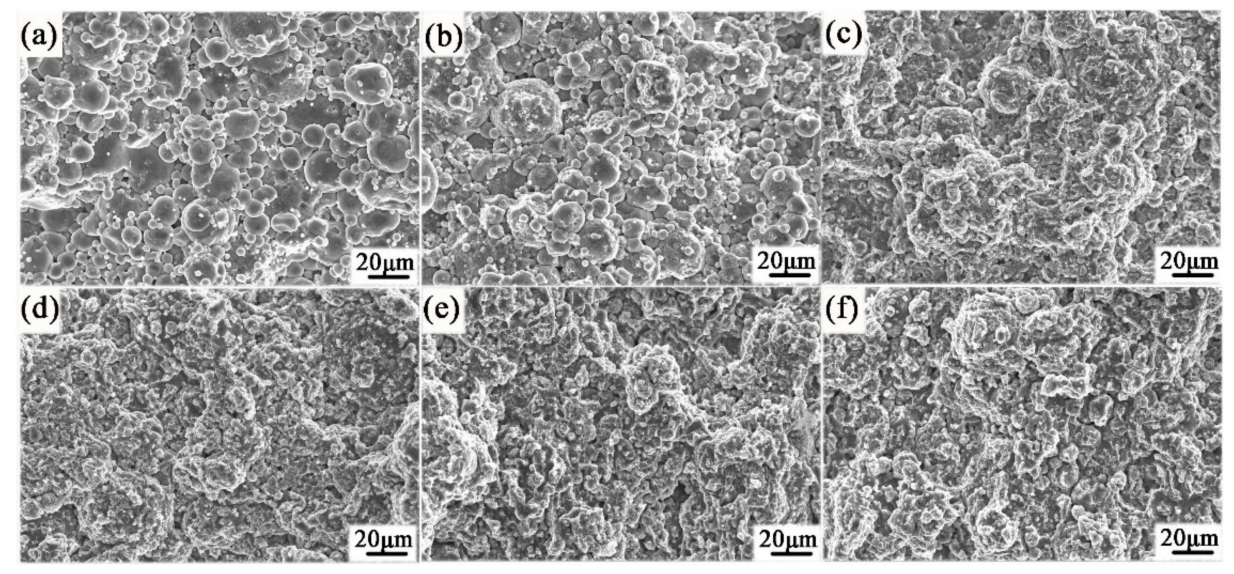

Figure 11. SEM/SE micrograph of fracture surface with different sintering temperature (a) $560{ }^{\circ} \mathrm{C}$ (b) $580{ }^{\circ} \mathrm{C}$ (c) $620^{\circ} \mathrm{C}$ (d) $640{ }^{\circ} \mathrm{C}[20]$ (e) $650{ }^{\circ} \mathrm{C}$ (f) $660{ }^{\circ} \mathrm{C}$.

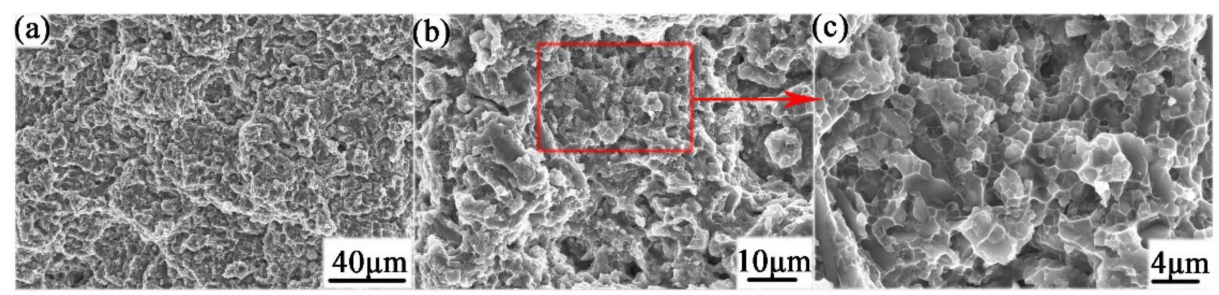

Figure 12. SEM/SE micrograph of fracture surface with compaction energy $1885 \mathrm{~J}$, (a-c) with different magnification. 


\section{Conclusions}

Thus, based on the results of the conducted study on HVC and sintered Al-based alloy powder with different sintering temperatures, it is possible to draw the main conclusion that $640{ }^{\circ} \mathrm{C}$ is rather effective for obtaining high-quality samples for Al-based alloy powder with the compaction energy of $1885 \mathrm{~J}$. More concrete conclusions are as follows:

1. For the green of Al-based alloy by HVC, the sintered density increased with the temperature increasing. When the compaction energy was $1885 \mathrm{~J}$, the samples sintered at $640{ }^{\circ} \mathrm{C}$ with a relative density of $98 \%$.

2. $\mathrm{XRD}$ of the sintered sample displayed the phases $\mathrm{Al}_{13} \mathrm{Fe}_{4}, \mathrm{Al}_{13} \mathrm{Cr}_{2}, \mathrm{Al}_{3} \mathrm{Ti}, \mathrm{AlN}$, $\mathrm{AlCr}_{2}$. TEM further verified the existence of intermetallic compounds $\mathrm{Al}_{13} \mathrm{Cr}_{2}, \mathrm{Al}_{3} \mathrm{Ti}$, and $\mathrm{Al}_{13} \mathrm{Fe}_{4}$.

3. The tensile properties of the sintered samples at $640{ }^{\circ} \mathrm{C}$ reached the maximum, UTS $222 \mathrm{MPa}$, YS $160 \mathrm{MPa}$, and the maximum $\delta 2.6 \%$ when the sample was compacted by the energy $1885 \mathrm{~J}$.

4. Fracture mechanism of the Al-based alloy was ductility fracture.

Author Contributions: Project administration, conceptualization and resources, X.Q. and H.Y.; investigation, methodology and validation, X.Y.; writing-original draft preparation, X.Y.; writtingreview and editing, Z.F., M.T., Z.Y. and Z.T. All authors have read and agreed to the published version of the manuscript.

Funding: This research was funded by the Key Scientific Research Projects Plan of Henan Higher Education Institutions, grant number 19A430017.

Institutional Review Board Statement: Not applicable.

Informed Consent Statement: Not applicable.

Data Availability Statement: All data generated or analysed during this study are included in this article.

Conflicts of Interest: The authors declare no conflict of interest.

\section{References}

1. Joshi, T.C.; Prakash, U.; Dabhade, V.V. Microstructural development during hot forging of Al 7075 powder. J. Alloy. Compd. 2015, 639, 123-130. [CrossRef]

2. Liu, B.; Liu, Z.; Liu, X. Effect of sintering temperature on the microstructure and mechanical properties of Ti50Ni50 and Ti47Ni47Al6 intermetallic alloys. J. Alloy. Compd. 2013, 578, 373-379. [CrossRef]

3. Dunnett, K.S.; Mueller, R.M.; Bishop, D.P. Development of Al-Ni-Mg-(Cu) aluminium P/M alloys. J. Mater. Process. Tech. 2008, 198, 31-40. [CrossRef]

4. Harding, M.D.; Donaldson, I.W.; Hexemer, R.L., Jr. Characterization of the microstructure, mechanical properties, and shot peening response of an industrially processed Al-Zn-Mg-Cu PM alloy. J. Mater. Process. Tech. 2015, 221, 31-39. [CrossRef]

5. Boland, C.D.; Hexemer, R.L., Jr.; Donaldson, I.W.; Bishop, D.P. Industrial processing of a novel Al-Cu-Mg powder metallurgy alloy. Mater. Sci. Eng. A. 2013, 559, 902-908. [CrossRef]

6. Wang, L.D.; Wang, L.M.; Cao, Z.Y. Synthesis, microstructures and properties of Al89Fe8Ti2Zr1 alloy prepared by powder metallurgy and hot extrusion. Mater. Res. Innov. 2016, 19, 65-68. [CrossRef]

7. Cooke, R.W.; Hexemer, R.L., Jr.; Donaldson, I.W.; Bishop, D.P. Press-and-sinter processing of a PM counterpart to wrought aluminium 2618. J. Mater. Process. Technol. 2016, 230, 72-79. [CrossRef]

8. Harding, M.D.; Donaldson, I.W.; Hexemer, R.L., Jr.; Bishop, D.P. Effects of Post-Sinter Processing on an Al-Zn-Mg-Cu Powder Metallurgy Alloy. Metals 2017, 7, 370. [CrossRef]

9. Gregory, A.W.S.; Mary, A.W.; Alan, T.; Richard, L.H.; Donaldson, I.W.; Bishop, D.P. Thermal Mechanical Processing of Press and Sinter Al-Cu-Mg-Sn-(AlN) Metal Matrix Composite Materials. Metals 2018, 8, 480. [CrossRef]

10. Mann, R.E.D.; Hexemer, R.L., Jr.; Donaldson, I.W.; Bishop, D.P. Hot deformation of an Al-Cu-Mg powder metallurgy alloy. Mater. Sci. Eng. 2011, 528, 5476-5483. [CrossRef]

11. Zhang, J.; Zhou, X.J.; Zhang, K. Quantitative investigation into the relation between force chains and stress transmission during high-velocity compaction of powder. J. Korean Phys. Soc. 2019, 74, 660-673. [CrossRef]

12. Yuan, X.J.; Yin, H.Q.; Dill, R.U.; Khan, D.F.; Qu, X.H. Study on the impact force and green properties of high-velocity compacted aluminium alloy powder. Int. J. Min. Metall. Mater. 2012, 19, 1107-1113. [CrossRef] 
13. Zhang, H.Z.; Zhang, L.; Dong, G.Q.; Liu, Z.W.; Qin, M.L.; Qu, X.H.; Lü, Y.Z. Effects of annealing on high velocity compaction behavior and mechanical properties of iron-base PM alloy. Powder Technol. 2016, 288, 435-440. [CrossRef]

14. Zhang, K.Q.; Yin, H.Q.; Jiang, X.; Liu, X.Q.; He, F.; Deng, Z.H.; Khan, D.F.; Zheng, Q.J.; Qu, X.H. A novel approach to predict green density by high-velocity compaction based on the materials informatics method. Int. J. Min. Metall. Mater. 2019, 2, 194-201. [CrossRef]

15. You, D.D.; Liu, D.H.; Guan, H.J.; Huang, Q.Y.; Xiao, Z.Y.; Chao, Y. A Control Method of High impact energy and cosimulation in powder high-velocity compaction. Adv. Mater. Sci. Eng. 2018, 2010, 1-11. [CrossRef]

16. Wang, Z.; Prashanth, K.G.; Zhang, W.W.; Scudino, S.; Eckert, J. Removing the oxide layer in a nanostructured aluminium alloy by localshear deformation between nanoscale phases. Powder Technol. 2019, 343, 733-737. [CrossRef]

17. Ibrahim, A.; Bishop, D.P.; Kipouros, G.J. Sinterability and characterization of commercial aluminium powder metallurgy alloy Alumix 321. Powder Technol. 2015, 279, 106-112. [CrossRef]

18. Huang, P.Y. Principle of Powder Metallurgy, 2nd ed.; Metallurgical Industry Press: Beijing, China, 2011.

19. Zhang, G.; Feng, K.; Li, Y. Effects of sintering process on preparing iron-based friction material directly from vanadium-bearing titanomagnetite concentrates. Mater. Des. 2015, 86, 616-620. [CrossRef]

20. Yuan, X.J.; Qu, X.H.; Yin, H.Q.; Yan, Z.W.; Tan, Z.J. Effects of compaction velocity on the sinterability of Al-Fe-Cr-Ti PM alloy. Materials 2019, 12, 3005. [CrossRef]

21. German, R.M. Powder Metallurgy and Particulate Materials Processing, 3rd ed.; Sintering concepts; Metal Powder Industries Federation: Princeton, NJ, USA, 2005.

22. Hao, G.L.; Li, X.Y.; Wang, W.G. Low frequency damping behavior associated with sintering process in $\mathrm{Al}$ powder compact. Trans. Nonferrous Metal. Soc. 2016, 26, 1176-1182. [CrossRef]

23. Mosher, W.G.; Kipouros, G.J.; Caley, W.F.; Bishop, D.P. On development of hypoeutectic aluminium-silicon powder metallurgy alloy. Powder Metall. 2011, 54, 432-439. [CrossRef]

24. Galano, M.; Audebert, F.; Stone, I.C.; Cantor, B. Nanoquasicrystalline Al-Fe-Cr-based alloys, Part I: Phase transformations. Acta Mater. 2009, 57, 5107-5119. [CrossRef]

25. Trunov, M.A.; Schoenitz, M.; Zhu, X.; Dreizin, E.L. Effect of polymorphic phase transformations in Al2O3 film on oxidation kinetics of aluminum powders. Combust. Flame 2005, 140, 310-318. [CrossRef]

26. Cao, L.; Zeng, W.; Xie, Y.; Liang, J.; Zhang, D. Effect of powder oxidation on interparticle boundaries and mechanical properties of bulk Al prepared by spark plasma sintering of Al powder. Mater. Sci. Eng. A. 2019, 742, 305-308. [CrossRef]

27. Schaffer, G.B.; Huo, S.H.; Drennan, J.; Auchterlongie, G.J. The effect of trace elements on the sintering of an Al-Zn-Mg-Cu alloy. Acta Mater. 2001, 49, 2671-2678. [CrossRef]

28. Yan, M.; Yu, P.; Schaffer, G.B.; Qian, M. Secondary phases and interfaces in a nitrogen-atmosphere sintered Al alloy: Transmission electron microscopy evidence for the formation of AlN during liquid phase sintering. Acta Mater. 2010, 58, 5667-5674. [CrossRef]

29. Li, H.; Yin, H.Q.; Khan, D.F.; Cao, H.Q.; Abideen, Z.; Qu, X.H. High velocity compaction of 0.9Al2O3/Cu composite powder. Mater. Des. 2014, 57, 546-550. [CrossRef]

30. Galano, M.; Marsh, A.; Audebert, F.; Xu, W.; Ramundo, M. Nanoquasicrystalline Al-based matrix/ $\gamma$-Al2O3 nanocomposites. J. Alloy. Compd. 2015, 643, S99-S106. [CrossRef] 